\title{
PROTOTYPE GAME BERBASIS VIRTUAL REALITY (VR) KARAKTER “JASPER"
}

\author{
Rina Alfah ${ }^{1, a}$, Mayang Sari', ${ }^{2, b}$ Muhammad Ridha Aulia ${ }^{3, c}$ \\ ${ }^{1} \mathrm{JI}$ Keramat Basirih No.47 Banjarmasin, \\ 2 Jl. Martapura lama km.10,4 komp shalli messi cluster 2 jalur 4 no 126 Banjarmasin, \\ ${ }^{3}$ Jl.belitung darat, komplek akasia No.1 Rt.12 Rw.02 Banjarmasin \\ a rinaalfah@gmail.com, b mayangsari.uniska@gmail.com, c mister.enchen@gmail.com
}

\begin{abstract}
Abstrak
Salah satu genre game yang diminati saat ini adalah game endless runner yang bisa dimainkan secara mobile. Untuk memenuhi kebutuhan teknologi dalam rekayasa game, maka kami mengangkat tema game endless runner sebagai salah satu game yang bisa di mainkan menggunakan Virtual Reality (VR) yang bisa mendeteksi gerakan user. Karakter utama berupa seorang laki-laki dengan enemy berupa anjing dan beberapa rintangan. Penelitian ini menggunakan Unity 3D sebagai game engine yaitu membuat game ini dengan tambahan tools tambahan yang berguna mengembangkan game ini.
\end{abstract}

Kata kunci : Endless Runner, Unity 3D, Virtul Reality

\begin{abstract}
One of the most popular game genres today is the endless runner game that can be played on mobile. To meet the technological needs in game engineering, we raised the theme of the endless runner game as one of the games that can be played using Virtual Reality (VR) which can detect user movements. The main character is a man with enemies in the form of dogs and several obstacles. This study uses Unity 3D as a game engine, namely making this game with additional tools that are useful for developing this game.
\end{abstract}

Keywords: Endless Runner, Unity 3D, Virtul Reality

\section{PENDAHULUAN}

Perkembangan Game berbasis android dan mobile saat ini sangat lah cepat dan variatif. Game dibutuhkan untuk menghilangkan jenuh akan kesibukan rutin dan aktifitas. User atau player sebutan untuk pemain game sangat memerlukan Skill dan strategi, kesempatan, maupun keberuntungan. Sebuah Game dapat kita mainkan secara multiple players ataupun single player. single player adalah jenis player game yang memiliki jenis tantangan yang unik, dimana pemain akan menggunakan keterampilannya sendiri untuk melawan waktu/kemungkinan.
Endless Runner merupakan genre yang sangat populer sejak smartphone mulai digunakan masyarakat, terutama yang berbasis android. Game ini menyajikan permainan yang sederhana di mana sebuah karakter di kendalikan , terus berlari dan pemain harus menentukan kapan harus melompat atau menghindari berbagai rintangan. Genre seperti ini memang terkesan sanagt sederhana, akan tetapi gameplay yang disuguhkan menjadi terasa sangat adiktif, jadi game seperti ini sangat cocok dengan tampilan layar Virtual Reality (VR) yang bisa mensimulasikan apa yang dilihat melalui mata karakter 
yang dimainkan. Dengan VR, Kita seolah-olah berada didalam permainan. Virtual Reality (VR) memunculkan gambar 3 (tiga) Dimensi yang di hasilkan Smartphone/ komputer, yang akan terlihat nyata dengan adanya bantuan sebuah alat dengan model seperti teropong . dengan teknologi ini , manusia yang akan merasakan dunia maya tetapi seperti dunia nyata.

Ketika kita mempunyai berbagai macam peralatan virtual reality (VR), Seolah panca indera kita bisa merasakan dalam lingkungan tersebut, tetapi jika peralatan dilepas, maka terasa bahwa sebenarnya hanyalah dunia virtual yang sangat mirip kenyataan. Dari fenomena Tersebut, maka penelitian ini dilakukan agar dapat menambah referensi permainan Basic sebuah game bergenre Endless runner tetapi berbasis headset Virtual reality (VR).

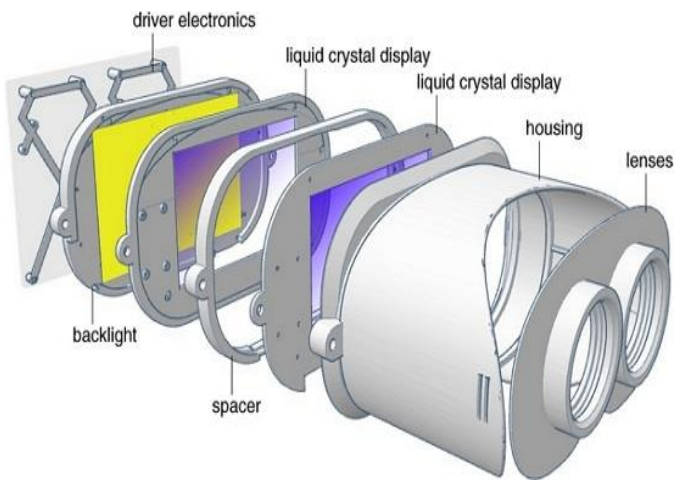

Gambar 1 Ilustrasi Headset Virtual reality (VR)

Sumber : Google

\section{METODE PENELITIAN}

Analisis untuk kebutuhan sistem nya, yaitu memahami dengan sebenarbenarnya kebutuhan dari sebuah sistem baru dan mengembangkan sistem yang melengkapi kebutuhan tersebut . Kebutuhan sistem terdiri dari Kebutuhan Fungsional atau Functional Requirement yang berisi proses yang harus dilakukan oleh sebuah sistem dan informasi yang harus ada di dalam sistem tersebut, sedangkan Kebutuhan Non Fungsional atau Nonfunctional Requirement adalah tipe kebutuhan yang berisi properti perilaku yang dimiliki oleh sebuah sistem.

Sedangkan Analisis Fungsional, dibentuk suatu rancangan konsep/rincian permainan yang dapat menarik perhatian pemain. Seperti:Jenis permainan, Sistem permainan dan Konsep cara bermain. Untuk Jenis permainannya adalah endless running yaitu type mode sederhana untuk refresh otak agar tidak jenuh. Sistemnya menggunakan smartphone android dan headset virtual reality (VR) . Konsepnya Player /pemain akan dikejar oleh anjing sehingga harus berlari supaya tidak digigit anjing dan menghindari berbagai rintangan yang ada didepan.

Untuk Kebutuhan analisis Non Funfsional , Analisis non-fungsional sistem merupakan paparan mengenai kebutuhan perangkat keras dan perangkat lunak dalam membuat sistem. Adapun kebutuhan dari game Endless Runner ini adalah :

1. Kebutuhan Perangkat Keras (hardware)

Perangkat keras yang digunakan dalam penelitian ini adalah : 1 unit headset VR, 1 unit komputer dengan spesifikasi setara minimal AMD Athlon(tm) II X2 255CPU processor (2 CPUs), RAM 4GB, mouse, modem, speaker, keyboard.

2. Kebutuhan Perangkat Lunak (software)

Perangkat lunak yang digunakan dalam penelitian ini adalah : untuk rancang bangun pembuatan laporan menggunakan Sistem Operasi Windows 7 Pro 64 bit, Java Development Kit (JDK) 1.8.0_131, Android Studio 2.3.3, Unity ver 5.6, GoogleVR, Monodevelope.

3. Kebutuhan Perangkat Keras Pemain

Perangkat keras yang dibutuhkan pemain untuk menjalankan game ini adalah : 1 unit android smartphone, 
memiliki RAM sebesar 1 GB, memory internal sebesar $500 \mathrm{MB}$, headset VR.

4. Kebutuhan Perangkat Lunak Pemain

Perangkat lunak yang dibutuhkan pemain untuk menjalankan aplikasi ini adalah : smartphone dengan sistem operasi android dengan versi minimal android 4.4 (Kitkat)

Untuk algoritma yang disajikan dengan gambar adalah dengan flowchart. Flowcart adalah bagan (chart) yang menunjukkan alir (flow) di dalam program atau merupakan prosedur sistem secara logika. Flowcart digunakan untuk alat bantu komunikasi dan untuk dokumentasi. Algoritma yang digunakan :

1. Start

2. Splash Screen

3. Tampilkan Menu Utama

4. Memilih Button, jika memilih button mulai lanjutkan langkah 5, jika memilih button keluar maka stop

5. Memulai permainan

6. Memunculkan musuh

7. Menggerakkan player, jika berhasil menghindar lanjut permainan, jika tidak menampilkan lanjut langkah 8

8. Menampilkan deathmenu, jika memilih button play again kembali ke langkah 5, jika memilih button menu kembali kelangkah 3

9. stop

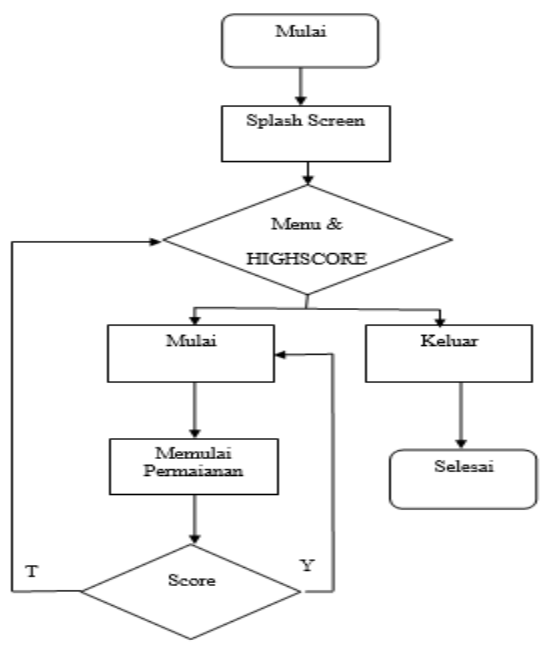

Gambar 2 Flowchart Game yang dibuat Sumber : Pribadi

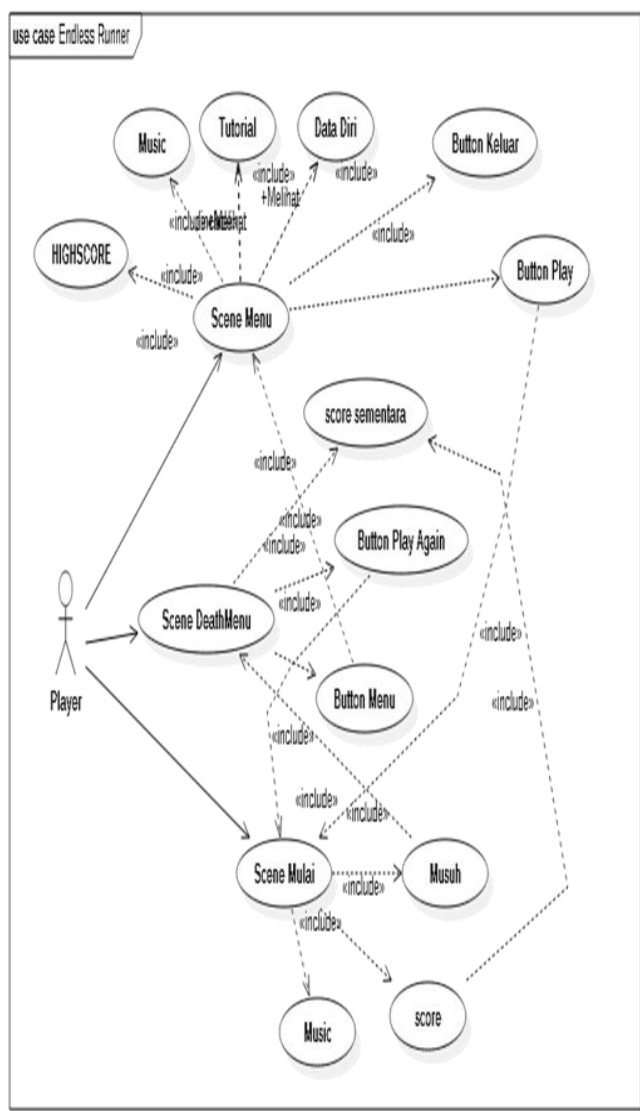

Gambar 3 Usecase Diagram

Sumber : Pribadi

Definisi use case berfungsi untuk menjelaskan fungsi use case yang terdapat pada use case diagram. Definisi use case diterangkan di bawah ini :

1 Scene Menu Awal Tampilan saat game dijalankan

2 Music Memainkan musik diawal

3 Tutorial Berfungsi menampilkan cara bermain

4 Data Diri Berfungsi Menampilkan data diri Pembuat Game

5 Button Keluar Berfungsi untuk keluar dari game

6 Button Play Untuk memainkan game

7 Scene Mulai Dimana game ini dimainkan

8 Musuh Adalah rintangan yang harus dihindari oleh player

9 score Adalah hasil yang diperoleh berapa lama player bertahan dalam game 
10 Scene DeathMenu Ketika player terkena musuh akan dikirim ke scene deathmenu

11 Score sementara Berfungsi untuk menampilkan score kita saat mati

12 Button Play Again Berfungsi untuk bermain kembali game

13 Button Menu Berfungsi untuk kembali Ke Scene Menu

14 HIGHSCORE Berfungsi untuk menampilkan hasil score player yang paling tinggi.

\section{HASIL DAN PEMBAHASAN}

Berikut adalah tabel Perangkat Lunak Pembangun sistem yang dibuat :

Tabel 1 Software Pembangun Sistem

\begin{tabular}{|c|c|c|c|}
\hline No & $\begin{array}{c}\text { Perangkat } \\
\text { Lunak }\end{array}$ & Spesifikasi & Keterangan \\
\hline 1 & $\begin{array}{l}\text { Sistem } \\
\text { Operasi }\end{array}$ & Windows 7 & $\begin{array}{l}\text { Sebagai sistem } \\
\text { operasi yang } \\
\text { digunakan } \\
\text { peneliti untuk } \\
\text { membangun } \\
\text { sistem. }\end{array}$ \\
\hline 2 & $\begin{array}{c}\text { Tool } \\
\text { Pembangun }\end{array}$ & UNITY 3D & $\begin{array}{l}\text { Software yang } \\
\text { digunakan } \\
\text { untuk } \\
\text { membangun } \\
\text { sistem. }\end{array}$ \\
\hline \multirow{3}{*}{3} & \multirow{3}{*}{$\begin{array}{c}\text { Tool } \\
\text { Tambahan }\end{array}$} & $\begin{array}{l}\text { Photoshop } \\
\text { CS } 3\end{array}$ & $\begin{array}{l}\text { Software yang } \\
\text { digunakan } \\
\text { untuk } \\
\text { mendesain } \\
\text { objek pada } \\
\text { sistem. }\end{array}$ \\
\hline & & $\begin{array}{l}\text { Android } \\
\text { Studio }\end{array}$ & $\begin{array}{l}\text { Software yang } \\
\text { digunakan } \\
\text { untuk } \\
\text { pengaturan } \\
\text { Android. } \\
\end{array}$ \\
\hline & & Google & $\begin{array}{l}\text { Software yang } \\
\text { digunakan } \\
\text { untuk mencari } \\
\text { tambahan } \\
\text { perangkat dan } \\
\text { desain. }\end{array}$ \\
\hline
\end{tabular}

\section{Hasil Antar Muka Sistem}

Untuk Material Game yang kami buat seperti gambar dibawah ini :

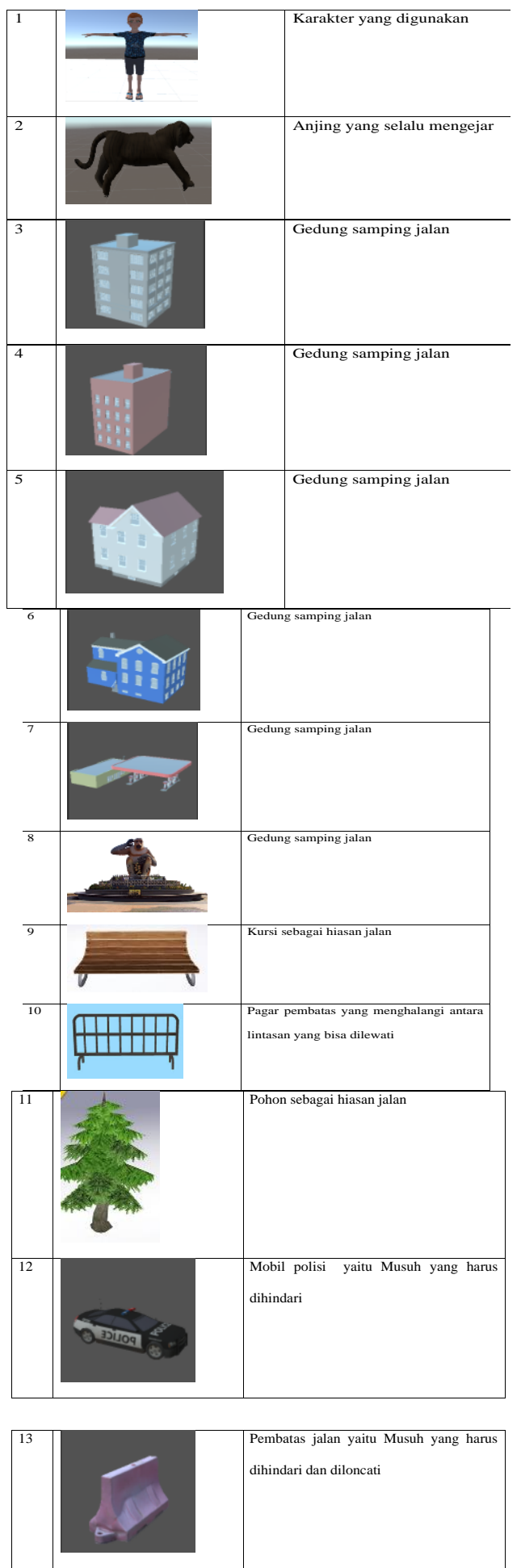

Gambar 4 Material Game Sumber : Pribadi

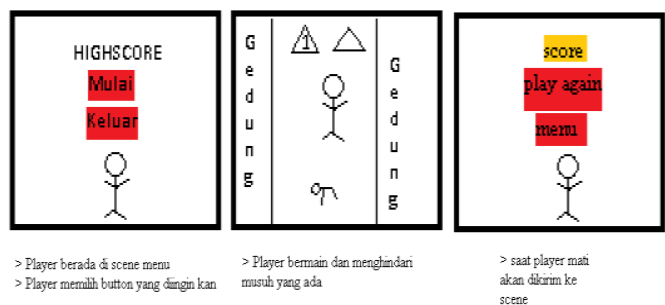


Gambar 5 Story Board

Sumber : Pribadi

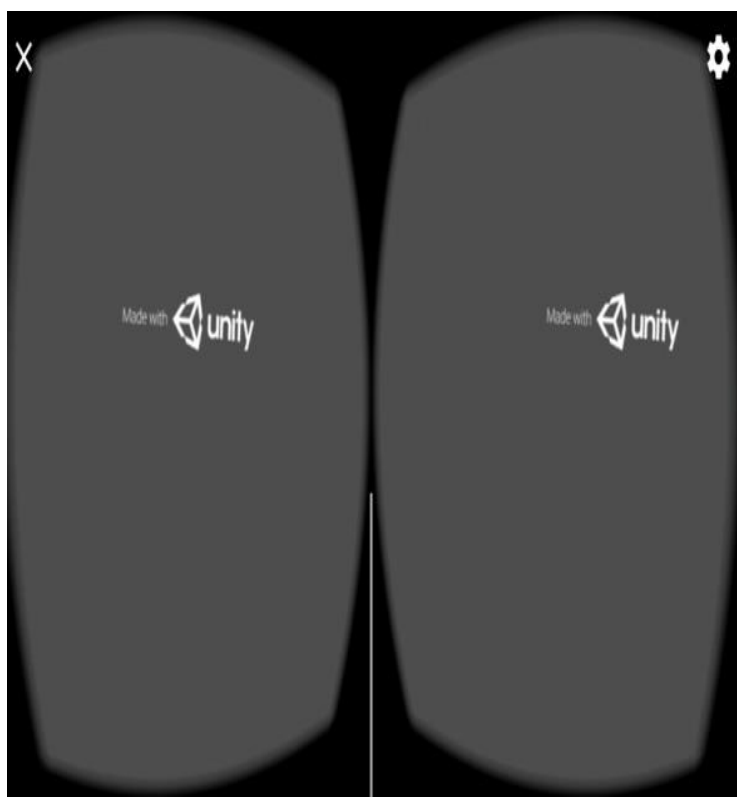

Gambar 6 Tampilan Splash Screen Sumber : Pribadi

Setelah halaman splash screen selesai, maka program otomatis langsung masuk ke scene menu, didalam scene menu terdapat beberapa bagian yaitu Highscore, button play, button exit,tutorial, data diri, dan logo uniska

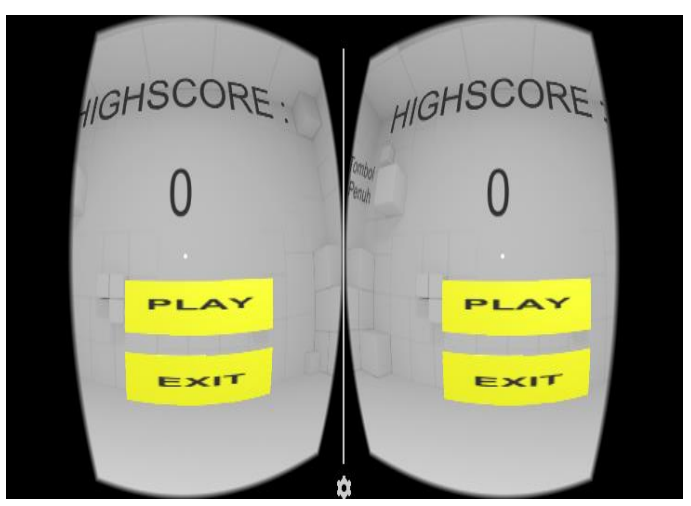

Gambar 7 Tampilan Depan Menu Sumber : Pribadi

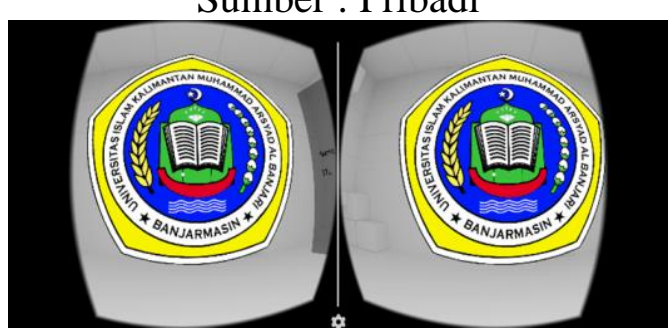

Gambar 8 Tampilan Belakang

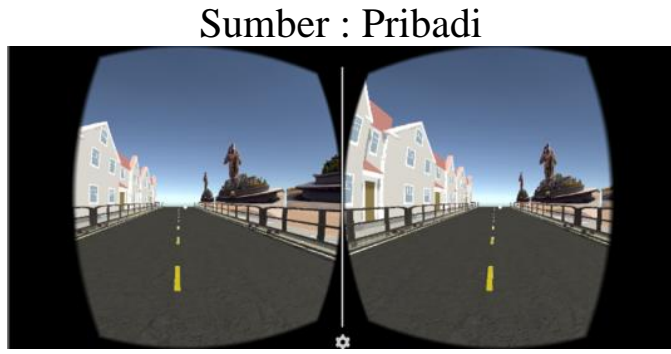

Gambar 9 Tampilan Start

Sumber : Pribadi

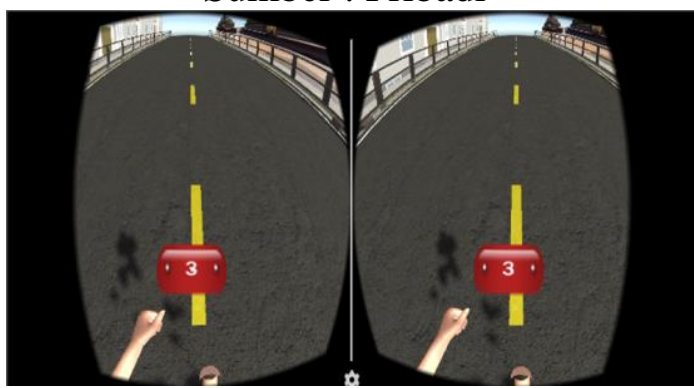

Gambar 10 Tampilan Start saat melihat ke bawah

Sumber : Pribadi

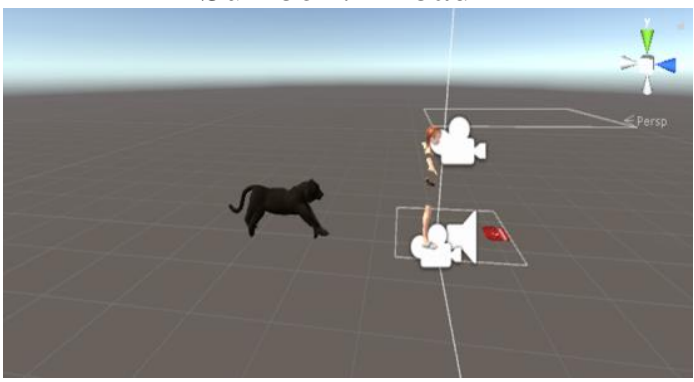

Gambar 11 Bagian Samping

Sumber : Pribadi

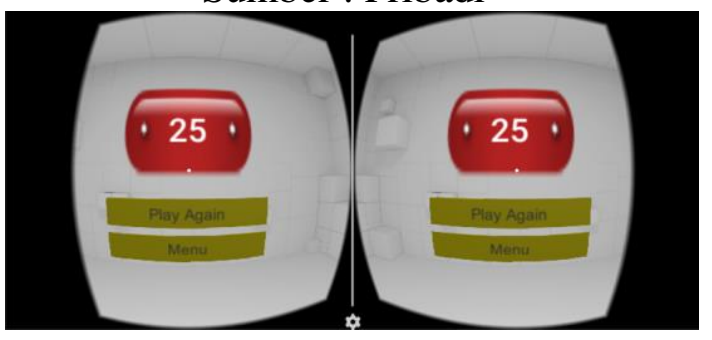

Gambar 12 Scene Deathmenu Sumber : Pribadi

Scene Deathmenu adalah saat player mati ketika bermain. Dan bagiannya adalah button play again, button menu, dan score saat mati.

\section{Pengujian Sistem}

Pengujian Game Endless Runner Dengan Virtual Reality Menggunakan Unity 3d ini menggunakan pengujian Alpha (Black Box). Dengan Pengujian 
ini akan menghasil produk dengan hasil yang diinginkan .

Tabel 2 Pengujian Scene Menu,Scene Mulai, Scene Death Menu

\begin{tabular}{|c|c|c|c|}
\hline \multicolumn{4}{|c|}{ Kasus dan Hasil Uji (Data Normal) } \\
\hline Aktivasi Pengülan & $\begin{array}{l}\text { Redilisasi Yang } \\
\text { diharapkan }\end{array}$ & Hasil Pengüjan & Kesimpulan \\
\hline $\begin{array}{c}\text { Menduklik Button } \\
\text { Play }\end{array}$ & $\begin{array}{c}\text { Gaze time berjalan } \\
\text { dan pindan ke } \\
\text { scene mulai }\end{array}$ & $\begin{array}{l}\text { Sesuaj yang } \\
\text { diharapkan }\end{array}$ & $\begin{array}{l}\text { [V]Diterima } \\
\text { [] Ditolak }\end{array}$ \\
\hline $\begin{array}{l}\text { Mengklik Buton } \\
\text { Keluar }\end{array}$ & $\begin{array}{l}\text { Gaze Time berialan } \\
\text { dan kelluar aplikasi }\end{array}$ & $\begin{array}{l}\text { Sesulai yang } \\
\text { diharapktan }\end{array}$ & $\begin{array}{l}\text { [V] Diterima } \\
\text { [] Ditolak }\end{array}$ \\
\hline \multicolumn{4}{|c|}{ Kasus dan Hasil Uji (Data Normal) } \\
\hline Aktivasi Pengujatan & $\begin{array}{l}\text { Realisasi Yang } \\
\text { dithrarphkan }\end{array}$ & Hasil Penguj]|an & Kesimpulan \\
\hline Berjalan & Plajer bergerak & $\begin{array}{l}\text { Seslaalyang } \\
\text { dilharapkan }\end{array}$ & $\begin{array}{l}\text { [V] Diterima } \\
\text { [ ] Ditolak }\end{array}$ \\
\hline $\begin{array}{l}\text { Melompat saat } \\
\text { menghadap atas }\end{array}$ & Player melompat & $\begin{array}{l}\text { Sesula yang } \\
\text { dilharapkan }\end{array}$ & $\begin{array}{l}{[V] \text { Diterima }} \\
{[\text { [ Ditolak }}\end{array}$ \\
\hline Mususuh dan jalan & $\begin{array}{l}\text { Musurh dan jalan } \\
\text { bercubah-ubath }\end{array}$ & $\begin{array}{l}\text { Sesula yang } \\
\text { dihlarapkan }\end{array}$ & $\begin{array}{l}\text { [V] Diterima } \\
\text { [ ] Ditolak }\end{array}$ \\
\hline Score bertambah & $\begin{array}{l}\text { Score yang berada } \\
\text { dibarivah bertambah }\end{array}$ & $\begin{array}{l}\text { Sesua yang } \\
\text { diharapkan }\end{array}$ & $\begin{array}{l}\text { [V] Diterima } \\
\text { [] Ditolak }\end{array}$ \\
\hline
\end{tabular}

Kasus dan Hasil Uji (Data Normal)

\begin{tabular}{|c|c|c|c|c|}
\hline $\begin{array}{c}\text { Aktivasi } \\
\text { Pengujian }\end{array}$ & $\begin{array}{c}\text { Realisasi Yang } \\
\text { diharapkan }\end{array}$ & Hasil Pen! & & Kesimpulan \\
\hline Score saat mati & $\begin{array}{ll}\text { Score saat } & \text { mati } \\
\text { sama } & \text { yang } \\
\text { dihasillkan } & \\
\end{array}$ & $\begin{array}{l}\text { Sesuai } \\
\text { diharapkan }\end{array}$ & & $\begin{array}{l}\text { [v] Diterima } \\
{[\text { [] Ditolak }}\end{array}$ \\
\hline $\begin{array}{l}\text { Mengklik Button } \\
\text { Play Again }\end{array}$ & 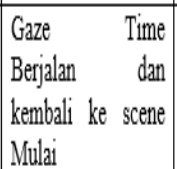 & $\begin{array}{l}\text { Sesuai } \\
\text { diharapkan }\end{array}$ & yang & $\begin{array}{l}{[\mathrm{y}] \text { Diterima }} \\
\text { [ ] Ditolak }\end{array}$ \\
\hline $\begin{array}{l}\text { Menglkik Button } \\
\text { Menu }\end{array}$ & $\begin{array}{l}\text { Gaze Time Berjalan } \\
\text { dan k kembali ke } \\
\text { scene menu }\end{array}$ & $\begin{array}{l}\text { Sesulai } \\
\text { diharapkan }\end{array}$ & yang & $\begin{array}{l}\text { [v] Diterima } \\
\text { [ ] Ditolak }\end{array}$ \\
\hline
\end{tabular}

\section{KESIMPULAN}

Prototype Game endless runner dengan tokoh seorang remaja, dengan berbagai rintangan menghasilkan sebuah aplikasi game berbasis Virtual Reality (VR) yang akan dinikmati pecinta game mobile karena kemudahan penggunaannya. Untuk penelitian kedepan nya dapat dibuat variasi game berbasis android lain seperti puzzle, advanture dan sebagai nya dengan penambahan variasi tokoh utama dan backsound music yang variatif.

\section{REFERENSI}

[1] Kevin Sutanto, (2016). Game Endless Running. Retrieved from https://id.techinasia.com/gameendless-runner-terbaik-untukandroid-dan-ios

[2] Koding Next, (2018). Virtual Reality.http://kodingnext.com/id/ virtual-reality-vr-dankegunaanya-dalam-kehidupan/

[3] David Liemanto Gunawan, Liliana, Gregorius Satia Budhi, (2016). Pembuatan Kebun Binatang Virtual Untuk PembelajaranMengenai Binatang Liar. Universitas Kristen Petra.

[4] Rina Alfah, T. V. R., 2018. Sistem E-Prescribing Dan BARCODE SYSTEM Untuk Resep Obat Di Rumah Sakit. Jurnal Teknologi Informasi Universitas Lambung Mangkurat (JTIULM), 03(Vol. 3 No. 2 (2018)), pp. 59-70.

[5] R Arya Wibowo, (2015). Endless Runner.

https://id.techinasia.com/game android-ios-endless-runner terbaik-2015.

[6] Rusdina, 2018. Perancangan Aplikasi Rawat Inap Di Klinik Bidan Sumirat, Pengaron Kalimantan Selatan. Balikpapan, Seminar Nasional Teknologi Informasi, Komunikasi Dan Administrasi (Seminastika) Universitas Mulia Balikpapan.

[7] N3K EN, (2015). Virtual Reality Coding.https://www.youtube.co $\mathrm{m} /$ channel/UCtQPCnbIB7SP_gM 1Xtv8bDQ/about.

[8] Wiku Baskoro, (2016). Jenis Genre Game. Retrieved from https://dailysocial.id/post/jenis- 
genre-game.

[9] Yohan Kurniadi, Liliana, Kristo Radion Purba, (2017). Pembuatan Aplikasi Simulasi Ujian Praktik Pengambilan Surat Izin Mengemudi Kendaraan Roda Empat. Universitas Kristen Petra.

[10] Refi Rufaidh, (2012). perbandingan Algortima Breadth First Search Pada Aplikasi Game Onet menggunakan Platform Android. Universitas Widyatama.

[11] Praja Irwandi, Aan Erlansari, Rusdi Effendi, (2016). Perancangan Game First Person Shooter (Fps) "Boar Hunter" Berbasis Virtual reality. Universitas Bengkulu. 